\title{
Empirical Study on University Curriculum Satisfaction of University Graduates
}

\author{
Haiyin Zhou \\ The Educational College, Shandong Normal University, Jinan, China \\ Email: haiyinzhou@163.com
}

Received 9 December 2015; accepted 25 January 2016; published 29 January 2016

Copyright (C) 2016 by author and Scientific Research Publishing Inc.

This work is licensed under the Creative Commons Attribution International License (CC BY). http://creativecommons.org/licenses/by/4.0/

c) (i) Open Access

\begin{abstract}
This research focused on the university curriculum satisfaction among college graduates and adopted the structure of close-ended and the Likert-Scale five-point measure questionnaire. This design is applied to 2795 graduates within three years of graduation from Shandong province. Results: On the whole, in Shandong province the level of satisfaction is not high, especially for the curriculum system and content. The degree of satisfaction of the postgraduates is higher than that of the employed students. Engineering graduates' satisfaction is lower than that of other three specialties.
\end{abstract}

\section{Keywords}

\section{Curriculum Satisfaction, University Graduates, Empirical Study}

\section{Introduction}

College curriculum satisfaction reflects the needs and expectations for college students and graduates. It includes curriculum aims, curriculum system and content, curriculum implementation, curriculum resources and curriculum evaluation and other aspects. College curriculum satisfaction is an important indicator to measure the quality of education in a university. Currently, the research on the college curriculum satisfaction is not enough [1]. Abroad researchers started the satisfaction survey from the beginning of 1980s. The results are mainly concentrated on the influence factors of the students' satisfaction, such as the academic level, learning style, learning objectives, learning expectations and learning experience and so on [2] [3].

In China, the earliest research on the curriculum satisfaction began in 2001 from Professor Xila Liu's survey in Tsinghua University, while the research on the degree of curriculum satisfaction in our country is still weak. Some scholars believe that the most major factors that affect the degree of students' satisfaction are the classroom disciplines and the preparations [4]. Some other scholars believe that the main factors that affect the de- 
gree of curriculum satisfaction are the curriculum system, teaching materials and reference books, teaching methods and means, teaching contents, teaching contents, teachers, examination and assessment method, teaching organization and management [5]. Therefore, some researchers investigated the free normal university students in the normal universities of the Ministry of Education from the curriculum planning, curriculum system, curriculum design, the opportunity to participate in curriculum design and the effect of the implementation of the curriculum and other aspects. The result shows that the degree of the satisfaction of the free normal students is low [6]. Moreover, there are also some other studies focused on college students' learning satisfaction, the results show that some utilitarian needs of college students and the micro factors in classroom interactions, such as teacher's teaching level and scientific research level, the teachers' suggestions and the students' opinion, are the important factors that affect the degree of satisfaction [7].

Through the study of the literature, most of the respondents are college students, but no research on graduates. However, the investigation of college graduates is undoubtedly very necessary. That is why we choose some of the graduates from 10 universities in Shandong province as our respondents.

\section{Methodology}

\subsection{Instrument}

This study adopts the structure of close-ended and the Likert-Scale five-point measure questionnaire. On the basis of a large number of domestic and foreign questionnaires, this research has 5 parts and 37 questions. Each item is given a 5 -point scale with $1=$ strongly disagree, $2=$ disagree, $3=$ slightly agree, $4=$ agree, and $5=$ strongly agree. Each questionnaire took 40 - 45 minutes to complete. The questionnaire was developed in Chinese. After testing, the Cronbach's $\alpha$ coefficients were above 0.8 .

\subsection{Participants}

According to the principle of convenience, we had a selective examination of 10 universities that directly under Shandong province, which includes three comprehensive universities, two technological universities, two normal universities, one science university, one agricultural university and one medical university. They are Qingdao University, Shandong University, Liaocheng University, Shandong Jianzhu University, Shandong Jiaotong University, Shandong University of Technology, Qingdao University of Science \& Technology, Shandong Normal University, Linyi University and Qufu Normal University. This study is based on college graduates within 3 years of graduation in Shandong province as the research objects. The respondents are between 22 and 26 years old, with a mean age of 24.5 years old, including 1083 postgraduates and 1718 employed students participate in this investigation. The specific distribution is shown in Table 1.

\subsection{Data Collection}

Data for the research were collected for 4 weeks. We recalled 2798 questionnaires, and selected the effective questionnaires according with the following criteria: 1) All of the questions are answered; 2) There is no inconsistent answer. After rejecting invalid questionnaires, there are 2795 questionnaires available.

\subsection{Data Analysis}

By examining the scores mean of every item, we analyzed all responses. To make conclusion, we examined all

Table 1. Distribution of participants.

\begin{tabular}{|c|c|c|c|c|c|}
\hline \multirow[b]{2}{*}{ Major } & \multicolumn{2}{|c|}{ Postgraduates } & \multicolumn{2}{|c|}{ Employed students } & \multirow{2}{*}{ Total } \\
\hline & Male & Female & Male & Female & \\
\hline Art & 87 & 235 & 153 & 296 & 771 \\
\hline Science & 182 & 198 & 256 & 261 & 897 \\
\hline Engineering & 97 & 126 & 266 & 140 & 629 \\
\hline Others & 68 & 90 & 186 & 160 & 504 \\
\hline \multirow{2}{*}{ Total } & 434 & 649 & 861 & 857 & 2801 \\
\hline & \multicolumn{2}{|c|}{1083} & \multicolumn{2}{|c|}{1718} & 2801 \\
\hline
\end{tabular}


data in numerical, graphical and tabular forms.

\section{Results}

\subsection{Descriptive Statistics}

The descriptive statistics of respondents were shown in Table 2.

From Table 2 we know that the mean value of the satisfaction is between 2.71 and 3.69, the "general" level in the five point scale, which indicates that the degree of satisfaction is relatively general.

The highest degree of satisfaction is 31. Your satisfaction with the library collections. 29. Your satisfaction with your school culture. 30. Your satisfaction with the multimedia teaching. All these questions belong to the "curriculum implementation" dimension. Next is the "curriculum resources" dimension, such as 26. Are you satisfied with the depth and breadth of your teachers' professional knowledge? 27. Your satisfaction with the teachers' academic levels and research capacities. 28. Are you satisfied with the chances and the effects in communicating with your teachers? The lowest degree of satisfaction: 11 . How many courses you are interested in and learn it patiently for many times from all of the classes? 12. If the periods of the practical courses are appropriate for you? 15. From your point of view, if the practice provided by your courses conforms the social activities? These questions belong to "curriculum system and content" and "curriculum evaluation" dimensions.

\subsection{The Satisfaction Difference between Graduate Students and Employed Students}

The average value of the five dimensions which given by the postgraduates and the employed students is shown in Figure 1.

Figure 1 shows that the degree of satisfaction of the postgraduates is higher than that of the employed students, but in the curriculum system and content, the postgraduates' degree is lower than the employed students'.

\subsection{The Satisfaction Difference among Different Specialty Graduates}

The average value of the curriculum satisfaction for different specialty graduates in the five dimensions is shown in Figure 2.

Figure 2 shows that different professional courses have different degrees of satisfaction, It is science, liberal arts, others, engineering arranging from high to low. In the curriculum aims, the highest satisfaction is science, the mean is 3.4423, Engineering is the lowest, the mean is 3.2311; In the curriculum system and content, the highest satisfaction is the "other" professional, the mean is 2.9881, the lowest is science, the mean is 2.7524; In the curriculum resources, the highest is science, the mean is 3.5641, the lowest is engineering, the mean is 3.3407; In the course of evaluation, the highest satisfaction is the "other" professional, the mean is 3.5238, the lowest is engineering, the mean is 3.1630; In the course of implementation, the highest satisfaction is the "other" professional, the mean is 3.8571 , the lowest is engineering, the mean is 3.4938 .

\section{Discussion}

Based on the results above, the university curriculum satisfaction is totally not high, Postgraduates' satisfaction is higher than employed students; the science graduates' satisfaction is higher than the students in liberal art, engineering and other subjects, meanwhile, engineering graduates have the lowest satisfaction. Among the postgraduates and the employed students, the lowest part of satisfaction is "curriculum system and content", which mainly appeared on the shortage of depth and breadth, frontier and the methodology. According to the questions 17 - 19: 17. Are you satisfied with the depth and breadth of your courses? $11.71 \%$ of students choose disagree or strongly disagree; 18. Do you think the course content is suitable for the subject frontier trends? $20.91 \%$ of students choose disagree and strongly disagree; 19. Are you satisfied with the course content on solving practical problems? $15.74 \%$ of students choose disagree and strongly disagree. The low satisfaction of all these items shows that the curriculum content tends to the subject-orientation only and neglects to reflect the dynamic frontiers, which cannot meet students' needs for the latest development of subjects. Especially the satisfaction of employed students is lower than postgraduates among this research. 11. How many courses you are interested in and learn it patiently for many times from all of the classes?; $48.47 \%$ of students choose disagree and strongly 
Table 2. Descriptive statistics of respondents.

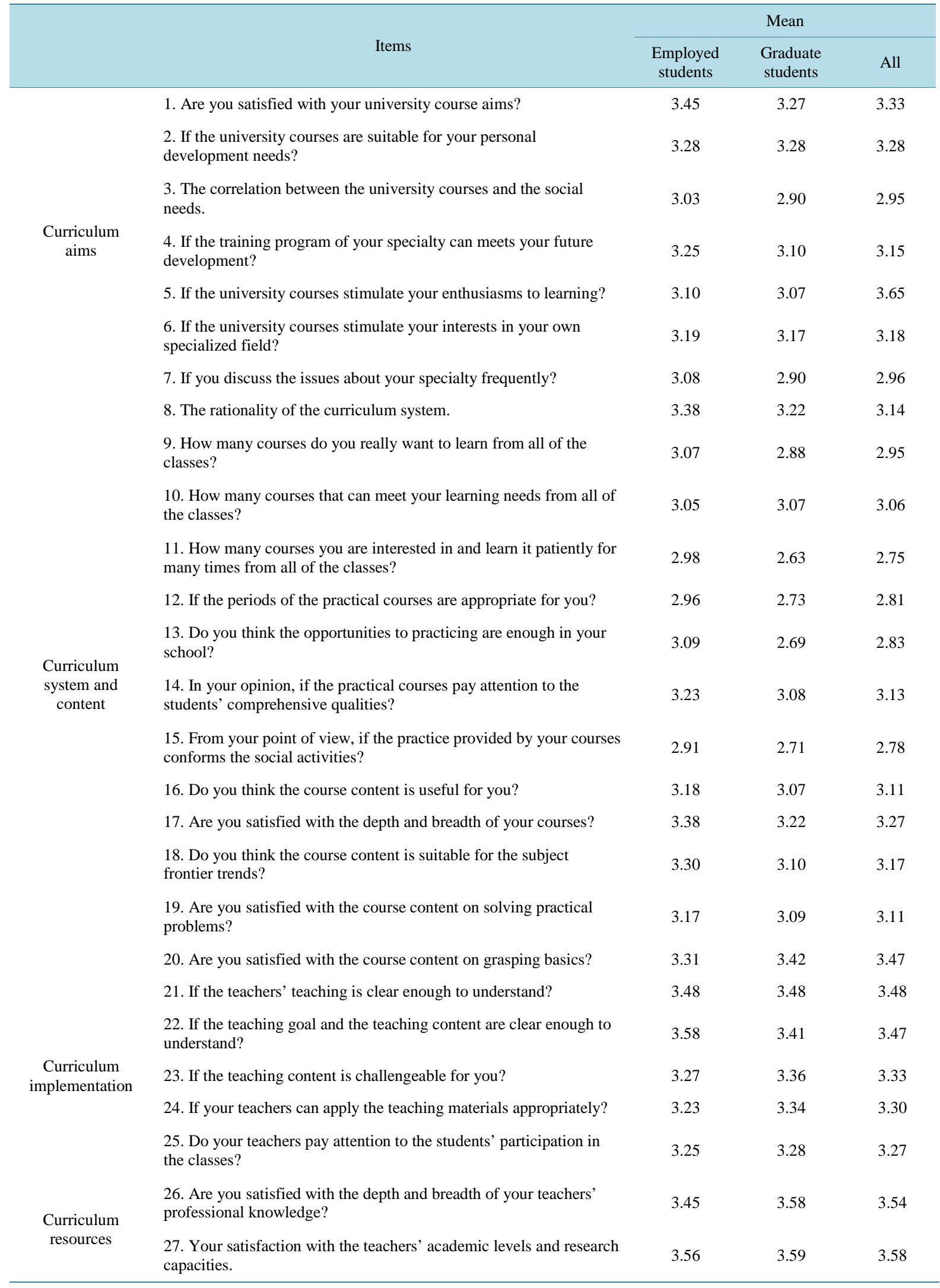




\section{Continued}

\begin{tabular}{|c|c|c|c|c|}
\hline & $\begin{array}{l}\text { 28. Are you satisfied with the chances and the effects in } \\
\text { communicating with your teachers? }\end{array}$ & 3.34 & 3.23 & 3.27 \\
\hline & 29. Your satisfaction with your school culture. & 3.58 & 3.61 & 3.60 \\
\hline & 30. Your satisfaction with the multimedia teaching. & 3.67 & 3.47 & 3.54 \\
\hline & 31. Your satisfaction with the library collections. & 3.69 & 3.67 & 3.68 \\
\hline & $\begin{array}{l}\text { 32. Your satisfaction with the teaching course wares and network } \\
\text { resources. }\end{array}$ & 3.55 & 3.53 & 3.54 \\
\hline & 33. Your satisfaction with selecting the teaching materials. & 3.42 & 3.36 & 3.38 \\
\hline & 34. Your satisfaction with the assessment methods. & 3.35 & 3.33 & 3.34 \\
\hline & 35. Do you think the course grades can reflect your learning levels? & 3.34 & 3.08 & 3.17 \\
\hline \multirow[t]{2}{*}{$\begin{array}{l}\text { Curriculum } \\
\text { evaluation }\end{array}$} & $\begin{array}{l}\text { 36. Do you think the examination contents and means can reflect the } \\
\text { course requirements? }\end{array}$ & 3.28 & 3.28 & 3.28 \\
\hline & $\begin{array}{l}\text { 37. How do you assess the undergraduate teaching quality of your } \\
\text { own department? }\end{array}$ & 3.46 & 3.58 & 3.54 \\
\hline
\end{tabular}

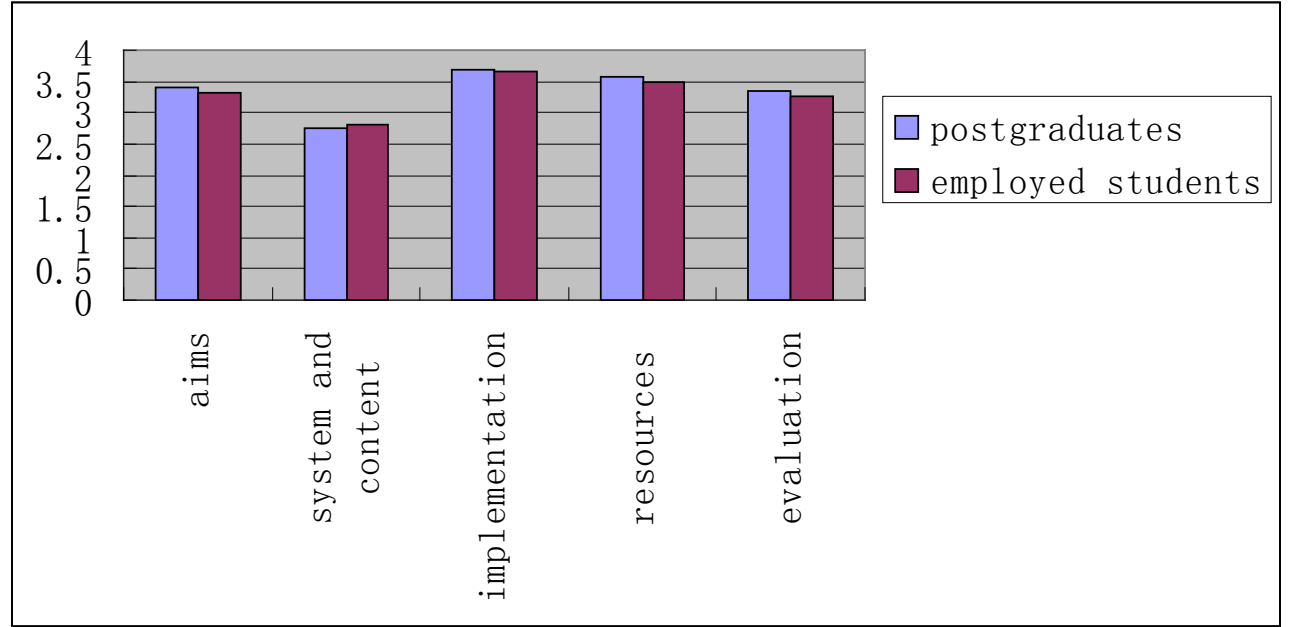

Figure 1. The satisfaction difference between graduate students and employed students.

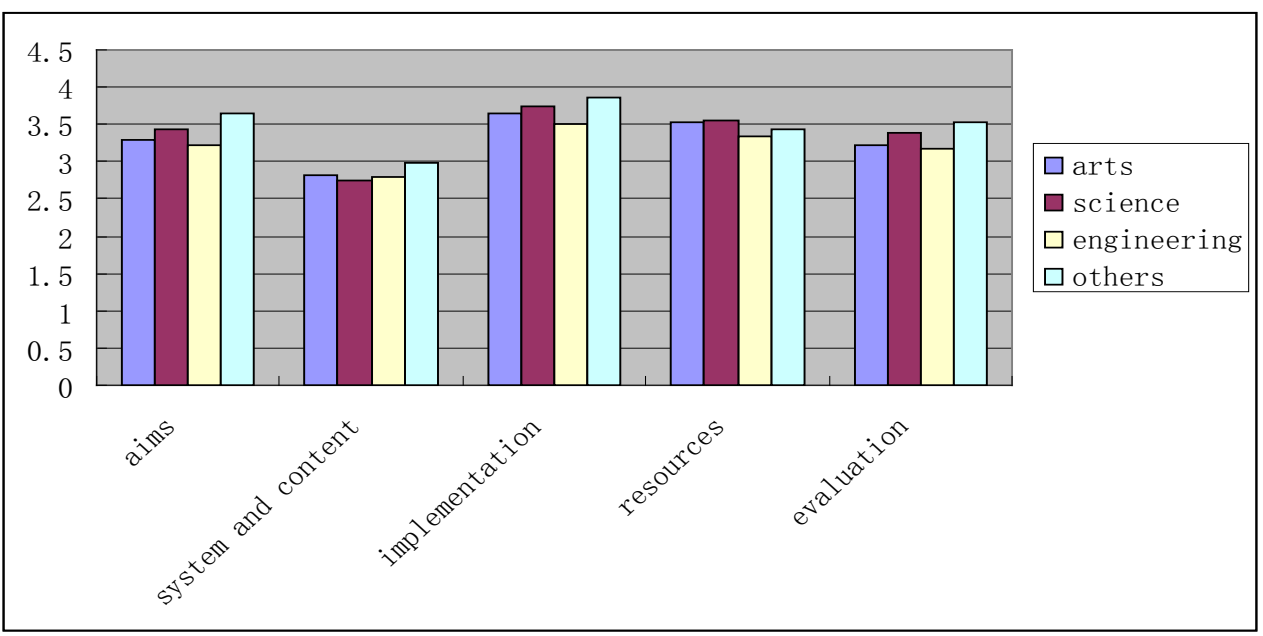

Figure 2. The satisfaction difference among different specialty graduates. 
disagree. 12. If the periods of the practical courses are appropriate for you? $43.36 \%$ of students choose disagree and strongly disagree; 13 . Do you think the opportunities to practicing are enough in your school? $35.47 \%$ of students choose disagree and strongly disagree; 14. In your opinion, if the practical courses pay attention to the students' comprehensive qualities? $29.08 \%$ of students choose disagree and strongly disagree; 15 . From your point of view, if the practice provided by your courses conforms the social activities? $43.88 \%$ of students choose disagree and strongly disagree; 16 . Do you think the course content is useful for you? $16.83 \%$ of students choose disagree and strongly disagree; The low satisfaction of these items shows that courses in universities are fragmented and out of reality, which lead students fail to grasp and build knowledge effectively.

\section{Conclusions}

Based on the research among those 10 universities above, the satisfaction of these five dimensions are obviously different: from high to low, curriculum implement, curriculum resources, curriculum aims, curriculum evaluation, curriculum system and content, respectively. Among these five dimensions, the curriculum system and content has the lowest satisfaction. The satisfaction of the employed students is lower than the postgraduates. The science curriculum has the highest degree of satisfaction, and the engineering curriculum has the lowest degree of satisfaction. According to this, the curriculum content and setting are not adapted to the current employment situation, especially for the students majoring in engineering. Thus there are some suggestions following: Firstly, curricula in universities should meet the needs of society and occupations. Curriculum settings should depend on students' abilities; Secondly, curriculum content should reflect the new knowledge and technological innovations quickly. The reason why the students majoring in engineering have the lowest satisfaction is that the engineering skills and technology have more practical needs. However, the integration of social information and industrialization of science and technology fails to enter the classrooms. It makes the curricula obviously fall behind the development of technology and the era. The curriculum content should reflect the frontier dynamic and aim to meet students' needs on the subjects of the latest. Finally, it is necessary to increase the interdisciplinary curricula and theories, which aims to broaden the students' visions. At the same time, the sharing of resources in different disciplines and institutions is also very essential.

This study also has some limitations due to the limited manpower: Firstly, this study only randomly investigated 2801 graduates from 10 universities in Shandong province as the research objects, the sample is quite small inevitably; Secondly, the classification of the professional category is somewhat rough; At last, there is no comparison between the graduates' satisfaction and the college students' satisfaction. These limitations are the problems I have to solve next.

\section{Funding}

Supported by "Shandong province innovation project: the effective teaching research based on the postgraduates' learning engagement” (SDYY15098).

\section{References}

[1] Zhou, H.Y. (2015) The Degree of the Course Construction in Universities. Educational Research, 10, 37-46.

[2] El Ansari, W. (2002) Student Nurse Satisfaction Levels with Their Course: Part II—Effects of Academic Variables. Nurse Education Today, 24, 171-180. http://dx.doi.org/10.1054/nedt.2001.0683

[3] Paechter, M., Maier, B. and Macher, D. (2010) Students' Expectation of, and Experiences in E-Learning: Their Relation to Learning Achievements and Course Satisfaction. Computers and Education, 54, 222-229. http://dx.doi.org/10.1016/j.compedu.2009.08.005

[4] Sun, Y.H. (2008) The Investigations and Analysis on the Degree of Satisfaction of Undergraduates under the Credit System. Statistical Education, 7, 55-59.

[5] Wei, H.R. (2009) The Investigation on the Degree of Satisfaction of Students in Normal University. Human Resource Management, 4, 118-120.

[6] Han, T., et al. (2008) Investigation and Analysis of the Free Normal Students. Liaoning Education Research, 9, 85-86.

[7] Li, G.Z. (2014) A Study on the Satisfaction of College Students. Journal of Higher Education Research, 3, 51-55. 